CORRECTION

https://doi.org/10.1038/s41586-019-0995-8

\title{
Publisher Correction: Glacial expansion of oxygen-depleted seawater in the eastern tropical Pacific
}

Babette A. A. Hoogakker, Zunli Lu, Natalie Umling,

Luke Jones, Xiaoli Zhou, Rosalind E. M. Rickaby,

Robert Thunell, Olivier Cartapanis \& Eric Galbraith

Correction to: Nature https://doi.org/10.1038/s41586-018-0589-x, published online 17 October 2018.

In this Letter, the position of the $y$ axes in Fig. $3 \mathrm{~b}$ was altered during the production process, and the carbon isotope label ' $\delta{ }^{13} \mathrm{C}$ ' was inadvertently changed to ' $\delta{ }^{18} \mathrm{C}$ '. In addition, the $x$ axis in Fig. $3 \mathrm{~b}$ is on a different scale; whereas this extends to $40 \mathrm{kyr}$ in Fig. $3 \mathrm{a}$ and c, it extends to $50 \mathrm{kyr}$ in Fig. 3b. This figure has been corrected online. 